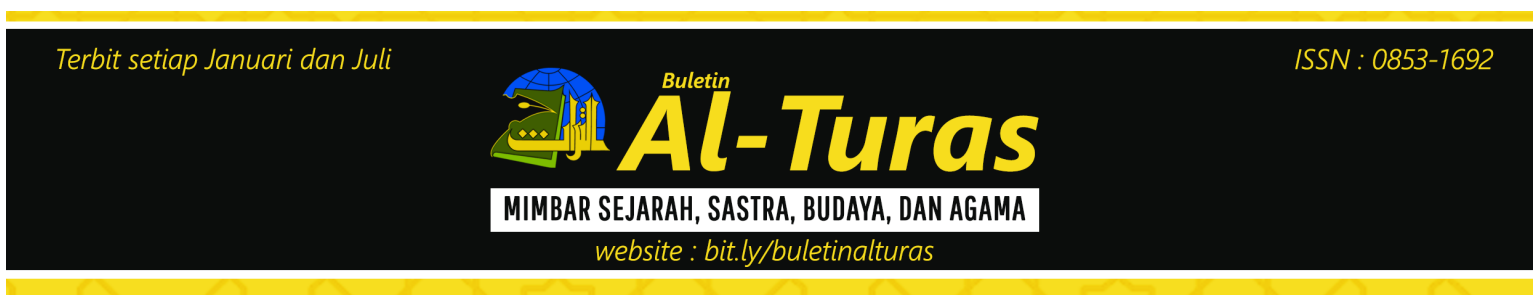

\title{
Model Diplomasi Kuno di Nusantara: Kasus Kesultanan Aceh dan Johor Abad XVI - XVII
}

\author{
Johan Wahyudi ${ }^{1}$
}

\begin{abstract}
Nusantara is the land with various old tales. There is remaining some historical facts that is still urgent to discuss. One of past theme that is interesting is the relation of kingdoms and lands. Aceh Darussalam is one of the greatest kingdom in Sumatra and the strait of Malaka. Their existence had regarded as the guard, but for the other groups see it as threat. In some cases, that outlook can be changing, depending on the regional political context.

The Kingdom of Johor becomes a one of political entity that is actively associated with Aceh. They need a strong colleague, in order to continue their development into estabilished kingdom. Their dark past, that is the fall of Malaka because Portuguese attack in 1511, is used for building a billateral cooperation with Aceh. Instead, the two kingdoms involved family relations. As we khow, marriage is the one of ancient diplomatic model in Middle Ages.

During the wheel of time, the diplomatic boundery between Aceh and Johor is not always on the line. At the one day, Johor had known that Aceh had another goal behind his intentions. Aceh had planned that Johor is part of Aceh's subordinate area. Therefore, Johor had decided Portuguese as his friend. This decision contraries to the vision of Aceh. Aceh had thougt that Portuguese is his rival. Aceh had showed his anger with several attacks to Johor.

This Paper will explain the model of ancient diplomacies, in case of the relation of Aceh and Johor. Some kind of that such as the diplomacy in politic and intellectual sphere.
\end{abstract}

Keywords: dynamic, diplomacy, marriage, personality and intellectuality

\section{Abstrak}

Nusantara merupakan ranah yang kaya akan kisah masa lalu. Di dalamnya terendap beragam peristiwa yang masih aktual dibicarakan. Satu tema yang menarik adalah mengenai hubungan kenegerian antarkerajaan. Aceh Darussalam merupakan salah satu kerajaan besar di Sumatera dan perairan Malaka. Keberadaannya dianggap pengayom, namun bagi kelompok lain, ia diangap sebagai ancaman. Pada titik tertentu, pandangan ini bisa saja berubah-ubah, tergantung pada kondisi politik regional.

Kesultanan Johor menjadi salah satu kesultanan yang aktif berhubungan dengan Aceh Darussalam. Johor membutuhkan rekanan yang tangguh, agar bisa terus berkembang menjadi kerajaan yang mapan. Masa lalu yang kelam, yakni dikuasainya Malaka oleh Portugis pada 1511, membulatkan tekad Johor untuk beriringan dengan Aceh dalam kerjasama bilateral. Malah, kedua kerajaan terikat oleh hubungan kekerabatan. Hal ini karena beberapa pangeran dan putri Johor menikah dengan pangeran dan putri dari Aceh. Seperti diketahui, pernikahan merupakan bentuk diplomasi kuno di Abad Pertengahan.

Dalam perjalanannya, diplomasi yang dijalin Aceh dan Johor tidaklah berjalan mulus. Pada satu keadaan, Johor menyadari bahwa Aceh mempunyai motif lain, yakni ingin menjadikan Johor bagian dari daerah pengaruhnya. Oleh sebab itu, Johor memutuskan menjalin hubungan dengan Portugis, agar bisa lepas dari bayang-bayang Aceh. Aceh yang memang menjadikan Portugis sebagai rivalnya, marah dengan kebijakan Johor. Sejak itu di beberapa fase hubungan Aceh dan Johor terlibat peperangan.

Tulisan ini akan mengangkat model dua diplomasi kuno seperti yang tersaji dalam kasus kerajaan Aceh dan Johor. Beberapa yang bisa disebutkan adalah diplomasi politik dan intelektual.

Kata kunci: dinamika, diplomasi, pernikahan, ketokohan dan intelektual

${ }^{1}$ Fakultas Adab dan Humaniora, Universitas Islam Negeri Syarif Hidayatullah Jakarta 


\section{A. Pendahuluan}

Komunikasi antara dua atau lebih entitas politik termasuk dalam kajian hubungan internasional. Meskipun begitu tema-tema mengenainya dapat pula ditemukan dalam peristiwa-peristiwa masa lalu. Studi diplomasi menjadi salah satu alat untuk membedah aneka ragam fenomena-fenomena mengenai bagaimana hubungan antara kerajaan, negeri maupun benua itu terjadi.

Langgam dari diplomasi kuno mempunyai bentuk yang bermacammacam. Modelnya bisa saja umum, namun di beberapa objek lain bersifat khas. Hal ini dikarenakan belum adanya aturan baku perihal penyelenggaraan hubungan diplomatik yang lebih administratif, terstruktur dan disepakati semua negara seperti sekarang ini. Indikator dari terhubungnya komunikasi dua raja atau kepala daerah adalah sejauh mana manfaat yang bisa dirasakan oleh kedua belah pihak.

Aceh Darussalam dan Johor merupakan dua kerajaan yang juga melakukan relasi diplomatik. Periode krusial dari hubungan mereka terjadi pada abad XVI dan XVII. Pada rentang waktu itu, terdapat beberapa peristiwa yang mewarnai relasi keduanya. Dari berbagai bentuk model diplomasi yang berlangsung saat itu, penulis tertarik untuk mengungkap dua model diplomasi, yakni diplomasi politik dan diplomasi intelektual.

\section{B. Pembahasan}

1. Jatuhnya Malaka
Kemunculan Portugis di panggung politik Asia Tenggara didorong oleh keinginan memperoleh komoditas utama di jajaran pulau Timur. Portugis merupakan bangsa yang menganggap penting arti pelayaran. Lisabon, ibukota Portugis, merupakan pusat pasar Eropa yang menghidupi ekonomi kerajaan. Pangeran Henry Sang Navigator, salah satu petinggi Kerajaan Portugis, berkeinginan bahwa kelak Portugis mempunyai armada dagang yang tangguh dan mampu berlayar ke dunia Timur untuk mendapatkan barangbarang eksotik dari Timur.

Pada tahun-tahun awal abad 15, Pangeran Henry membangun akademi kelautan yang menjadi motor studistudi kelautan, nautika dan perkapalan. Di sekolah ini, para calon angkatan laut dibekali pengetahuan mengenai bagaimana berlayar dengan baik, berikut apa yang dilakukan jika menghadapi masalah-masalah di lautan. Menjadi pembahasan yang juga dipaparkan, mengenai model kapal yang diyakini mampu berlayar dengan cepat. Beberapa waktu kemudian kapal-kapal itu berhasil diciptakan dan mulai mengadakan serangkaian percobaan-percobaan pelayaran hingga muncul keyakinan, armada Portugis akan mampu meluncur ke dunia Timur (Hendrik Willem van Loon: 1922, 218 - 219; Abdul Aziz bin Zakaria: 1953, 13 dan 17). Masa di mana Portugis menjelajah dunia di luar Eropa adalah pintu gerbang sejarah Eropa memasuki Abad Ekspansi (David Birmingham: 2003, 25).

Dunia Timur menjanjikan keunikan tersendiri. Dalam pandangan bangsa Eropa, Dunia Timur adalah tempat harta-harta alam yang terbesar. Di 
sana banyak tumbuhan serta kekayaan bernilai tinggi. Menjadi cita-cita tersendiri di benak kerajaan-kerajaan Eropa untuk bisa sampai ke pulaupulau di Timur. Dari belahan timur, para pedagang Arab, Persia India membawa cangkeh dari Timor, kapur barus dari Borneo, emas dan perak dari Luzon, barang-barang antik (porselin) dari Cina serta getah, parfum dan rempah-rempah ke pasar-pasar Eropa. Beberapa pasar Eropa yang dimaksud adalah Venezia, Genoa dan Catalonia (Manuel de Faria Y Souza: 1887, 19).

Fernand Braudel bertanya dengan sinis, bagaimana bisa peran pasar dikesampingkan dalam hasrat manusia? Pasar adalah pusat permintaan seklaigus pemenuhan kebutuhan hidup. Pasar Eropa di abad 15, menjanjikan kebebasan, keterbukaan akses untuk menghirup udara segar ke tempattempat yang amat jauh dari jangkauan mata. Merupakan kesulitan tersendiri dalam memetakan sejarah linear pasar. Pasar mencakup tradisi besar yang berlangsung di masa lalu, masa berikutnya bahkan sampai hari ini, masa ultra-modern. Tempat ini menjadi lokasi di mana banyak orang berkumpul, dan pembicaraan yang berlangsung di dalamnya tidak melulu soal ekonomi, tapi juga pemenuhan kebutuhan pribadi di luar lingkup ekonomi (Fernand Braudel: 1982, 26).

Di belahan Semenanjung Iberia lainnya, terdapat kerajaan yang juga berkeinginan membangun tradisi kemaritimannya. Ia adalah Spanyol. Mereka merasa mampu untuk membangun armada dagang yang juga tangguh. Spanyol dan Portugis terlibat dalam kompetisi perdagangan yang mengerucut pada kesamaan visi mereka untuk sampai ke dunia Timur. Untuk menyehatkan persaingan, keduanya menerima saran Paus Alexander VI dan menyelenggarakan perjanjian Tordesillas (7 Juni 1494). Perjanjian ini menegaskan bahwa sudah ada bagian dari tanah dan laut dunia ini untuk dua bangsa itu. belahan Barat bebas dilayari dan Spanyol, dan belahan Timur untuk Portugis (Thomas Duve: 2013, 1).

Sementara Spanyol mengarahkan kemudi kapal-kapalnya ke Barat Eropa, Portugis menyasar ke rute pelayaran menuju India. Portugis melewati beberapa pelabuhan di Afrika, hingga sampai ke Tanjung Harapan Baik (The Cape of The Good Hope). Dari situ, mereka mengarahkan lagi layarnya hingga sampai ke beberapa bandar dagang utama Asia. Salah satu pelabuhan utama Persia, Ormuz (Hormuz), berhasil mereka kuasai pada 1507 (Svat Soucek: 2008, 30). Wilayah baru itu tidak serta merta membuat mereka puas. Mereka melanjutkan pelayaran dagangm yang kemudian berubah mengusung semangat kapitulasi itu, ke Anak Benua India.

Di India, tepatnya pada 1510 , Portugis sempat mengalami perlawanan sengit dari penguasa Islam India. Perang yang berlarut-larut, sampai-sampai membawa Portugis pada bayangan malapetaka kekalahan. Mereka mulai menjajaki kerjasama dengan penguasa lokal yang beragama HIndu untuk membantu niat mereka. Dengan bantuan ini, perlahan, Portugis berhasil menyudutkan pasukan Muslim hingga akhirnya Portugis mendapat kemenangannya. Goa, bandar dagang ramai di Anak benua India akhirnya berbendera Portugal. Penaklukkan atas Goa dipimpin oleh 
Alfonso d' Albuquerque (Philip D. Curtin: 139; J. S. Jayne: 1910, 81-85).

Pendudukan Goa membuat Portugis semakin percaya diri meluaskan pengaruhnya ke Timur. Alfonso d'Albuquerque mendengar dari seorang pedagang Portugis bahwa Malaka adalah bandar dagang ramai. Sang pedagang ini juga menceritakan bahwa dirinya diberikan cendera mata indah dari Raja Malaka (Armando Coertesao: 2005, 268 - 275). Setelah mendengar keterangan itu, Alfonso pun tergerak untuk menyiapkan pelayaran selanjutnya untuk menguasai Malaka.

K. N. Chauduri melukiskan masa di mana Portugis giat melebarkan sayapnya di dunia belahan timur sebagai "Tahun Aktivitas Heroik." Di masa ini, Para raja Asia gigih mempertahakan wilayah-wilayah pantainya atas serbuan armada Portugis. Pertahanan mereka akhirnya mampu diterobos lawannya. Tentunya tidak semua wilayah pesisir didatangi Portugis. Hanya pesisir yang menyandang pangkat sebagai emporium saja yang dikuasainya. Beberapa emporium yang belakangan direbut Portugis seperti pelabuhan Afrika Timur, Malabar, Konkan, Teluk Persia dan terakhir selat Malaka (K.N. Chauduri: 1989, 66).

Setelah persiapan rampung, armada Portugis pimpinan Alfonso d' Albuquerqe bertolak menuju Malaka. Begitu sampai, kapal-kapal Portugis segera membuat formasi serangan. Beberapa waktu kemudian, meriammeriam Portugis pun memuntahkan tembakan yang langsung diarahkan ke pasar-pasar Malaka. Hantaman bertubitubi membuat penduduk dan pedagang di sana lari menyelamatkan diri. Toko- toko, rumah-rumah hancur diterjang bola besi panas Portugis. Dengan terburu-buru, pasukan Malaka bersiap mendekati bibir pantai, membentuk barisan pertahanan sembari melakukan perlawanan balik.

Begitu pasukan Portugis sampai di pantai, mereka segera disambut oleh amukan marah pasukan lawan. Pertempuran terjadi dengan sengitnya. Tamu tidak diundang yang memang berencana menguasai kota pelabuhan itu, tidak lagi membuang waktu. Mereka melancarkan serangan terorganisir hingga membuat lawannya kesulitan mengembangkan pertahanan. Oleh sebab serangan ini adalah mendadak, maka amat sempit waktu yang dimiliki Malaka untuk mencoba langkahlangkah lain mengamankan kotanya. Armada perang Portugis terlihat lebih siap mengalirkan strategi dan formasi untuk menguasai tempat-tempat yang dianggap vital. Tidak berselang lama, pelabuhan yang termashur di mata dunia itu sudah berada dalam genggaman orang Peranggi (sebutan naskah Melayu untuk Portugis).

Sultan Malaka saat itu, Mahmudsyah, berhasil melarikan diri dari prahara Portugis di kotanya. Ia dan keluarganya keluar Malaka menggunakan perahu kecil, menuju Pulau Bintang. Tidak lama di situ, ia berpindah ke beberapa tempat hingga sampai ke Kampar. Di sana, kedudukannya masihlah diakui sebagai Sultan Malaka yang sah. Penduduk Kampar bahkan menyatakan kesetiaannya untuk membela sang raja tanpa mahkota itu. Suatu ketika, Mahmudsyah merenung, ia tidak bisa menjalani hidup seperti ini terus. Ia berketetapan untuk membangun 
kerajaan lagi, menyelamatkan marwah raja-raja Malaka.

Setelah berpamitan dengan warga Kampar, rombongan Mahmudsyah berangkat ke Pahang. Sultan Pahang masih berkerabat dengan Mahmudsyah. Setelah beberapa waktu di Pahang, Mahmudsyah memutuskan menuju pinggir sungai Johor. Di sana ia mendirikan kesultanan Johor. Pemilihan lokasi di pinggir sungai menunjukan kerajaan ini akan mengandalkan pemasukan pendapatan melalui jalur perniagaan dan pelayaran. Lokasi sungai Johor sendiri langsung berhulu di selat Malaka, sehingga harapannya para pedagang dari wilayah Nusantara maupun mancanegara dapat bertransaksi ke kerajaan baru itu (Hamka: 1961, 140 $-143)$.

Literatur lain mengatakan bahwa Portugis, yang sejak awal tahu bahwa beberapa keluarga istana Malaka melarikan diri, tidak melewatkannya. Pada 1526, sepasukan Portugis datang ke pulau Bintang, karena disinyalir pulau ini pernah disinggahi keluarga Malaka. Merasa tidak mendapatkan orang-orang buruannya, pulau ini pun dihancurkan dan menyerahkannya kepada Raja Lingga. Mahmudsyah yang ternyata sudah beberapa waktu sebelumya meninggalkan pulau Bintang, melarikan diri ke Kampar. Di sini ia mempunyai keinginan untuk membangun pusat kekuasaan di Johor. Setelah persiapan usai rombongannya berangkat ke Johor. Sayang sekali, di tengah perjalanan Mahmudsyah mangkat pada 1528.

Alauddin, anak Mahmudsyah, didapuk menjadi pelanjut cita-cita ayahnya. Setelah membangun beberapa instalasi umum penting di Johor, ia menerima kabar bahwa Portugis sedang mengarah ke kerajaan barunya. Pertempuran pun tidak terelakkan, namun kali ini kedua pasukan bisa dikatakan imbang. Sejak itu, Johor menjadi duri dalam daging bagi upaya Portugis menanamkan pengaruhnya di semenanjung Melayu. Pertikaian dengan Portugis sempat mengalami masa surut pada 1536. Kala itu pasukan Portugis di bawah pimpinan Dom Estavao da Gama datang dan memaksa Johor berdamai dengan Portugis. Muzaffar Syah, kakak Alaudiin, tidak segera memutuskan. Ia meminta diri pergi ke Perak dan Pahang, mengajak kedua penguasanya untuk bersama berdamai dengan Portugis demi kelangsungan kerajaan. Ketiga kerajaan Melayu itu pun setuju menetapkan perdamaian bersyarat dengan Portugis (D.G.E. Hall: 1988, 309-310).

Terbit semangat baru di hati para pejabat Johor. Kendati kerajaan mereka baru lahir, mereka merasa sebagai kerajaan yang sudah lama berdaulat. Hal ini tidak bisa dilepaskan dari status mereka sebagai keluarga kerajaan Malaka atau orang-orang yang memegang peranan ke kerajaan baru ini, beberapa adalah mereka yang pernah bertugas di istana Malaka. Amat wajar jika di benak mereka bertekad membangkitkan kembali kewibawaan leluhur mereka, para raja Malaka, untuk kembali dihargai dan dihormati oleh negeri-negeri jiran.

2. Persinggungan Aceh, Johor dan Portugis

Menginjak medio awal abad 16, Aceh sudah menjadi salah satu kekuatan besar di Sumatera. Kerajaan ini besar karena berhasil memadukan perluasan pengaruh dan perdagangan barangbarang ekspor, seperti lada. Masa 
tatkala Portugis berhasil menduduki Malaka, hampir bersamaan dengan pengangkatan Sultan baru di tubuh Aceh Darussalam, yakni Sultan Ali Mughayyat Syah (memerintah 1511 1530). Tanpa membuang waktu, sang Sultan menjadikan perebutan Malaka dari tangan Portugis sebagai salah satu kebijakan internasional terpenting (Amirul Hadi: 2010, 37-39). Denys Lombard menyebutnya sebagai raja Aceh yang sebenar-benarnya (Denys Lombard: 1986, 49).

Di pihak lain, Portugis tidak hanya berdiam menunggu datangnya kapal dagang. Mereka aktif membangun komunikasi dengan kerajaan-kerajaan Melayu lainnya untuk memperkuat reputasi di hadapan para penguasa Melayu. Tercatat beberapa kerajaan menjadi sekutu Potugis, di antaranya adalah Daya, Pedir dan Pasai (Mohammad Said: 1981, 165 - 168). Terjadi kerjasama yang menguntungkan di antara mereka, baik di bidang politik maupun ekonomi. Para raja Melayu agaknya sudah menyadari bahwa Aceh berencana menjadi yang terdepan di kalangan penguasa Sumatera dan dunia Melayu. Oleh sebab itu, mereka menjalin aliansi dengan kekuatan lain yang dianggap sepadan dengan Aceh.

Aru menjadi salah satu kesultanan lain yang berhubungan baik dengan Portugis. Mengetahui hal ini, ketika pada 1539, sepasukan Aceh dikirimkan untuk memberi pelajaran kepada Raja Aru agar menjauhi orang Eropa itu. Sesampainya di sana, segera terjadi pertempuran. Pihak Aru sama sekali tidak menginginkan kedatangan Aceh di negerinya. Beberapa waktu kemudian, datang bala bantuan dari Johor.
Johor memandang Aru adalah masih kerabatnya, serangan atasnya, berarti serangan atas dirinya pula. Bantuan ini membuat pasukan Aceh tertahan dan mengundurkan diri. Ini merupakan awal pertemuan Aceh dan Johor. (Amirul Hadi: 2010, 7).

Pada tahun 1547, ketika Aceh diperintah oleh Sultan Alaiddin Riayat Syah alQahhar (memerintah 1537 - 1568), timbul hasrat Aceh untuk mengakhiri kuasa Portugis di Malaka. Setelah pasukan siaga, diberangkatkanlah mereka langsung ke jantung pertahanan Portugis di benteng Malaka. Pasukan lawan yang sudah mengetahui, sudah siap menyongsong serangan Aceh. Perang pun pecah dengan sengitnya. Pasukan Aceh menggempur dan mendorong mundur lawannya. Pada edisi kali ini, pasukan Aceh segera mengambil alih keadaan. Pasukan lawan dibuat bertahan di dalam bentengnya, bahkan sempat muncul kabar bahwa Portugis tidak lagi ingin melanjutkan pertempuran. Mengetahui musuhnya terdesak, pasukan Aceh pun memasang barikade pengepungan untuk semakin menyudutkan lawannya. Saat itu begitu sulit bagi Portugis, hingga bayangbayang kekalahan sudah amat dekat di depan mata.

Tanpa diketahui Aceh, dari tempat yang luput dari pengawasan, datang bantuan logistik ke dalam benteng Portugis. Bantuan itu diberikan oleh Johor, Perak dan Pahang. Setelah pasukan Portugis mendapat asupan makanan dan senjata yang cukup, mereka pun bersiap kembali menyongsong lawan di depan pintu benteng. Dari arah laut, kapal-kapal kerajaan Melayu menerjang dan menyerang armada Aceh. Aceh 
yang sama sekali tidak menghitung adanya bantuan ini dibuat kewalahan. Di daratan pasukan Portugis melakukan serangan balik. Konsentrasi terpecah, garis komando yang semula lancar dialirkan menjadi terputus, karena terbagi dalam dua fron. Perang edisi kali ini dimenangkan oleh Portugis dan sekutunya. Aceh berhasil dipukul mundur kembali ke ujung Sumatera (Amirul Hadi: 2010, 42).

Pada tanggal 20 Januari 1568, Aceh kembali memberangkatkan pasukannya menyerang Portugis di Malaka. Kali ini, pasukan Aceh diperkuat dengan bala bantuandariTurki.PasukanAcehkembali bisa menekan Portugis, sampai mereka harus bertahan di dalam bentengnya. Meskipun demikian, Penyerbuan ini masih belum menemukan hasil yang diharapkan (Amirul Hadi: 2010, 43). Telah dua episode ditampilkan, Aceh mengalami kesulitan untuk menerobos benteng Portugis di Malaka. Hal ini dikarenakan benteng Portugis dibangun dengan bahan material yang kokoh dan selalu dijaga ketat dengan pasukan, juga letaknya strategis yakni di satu sisi berbatasan langsung dengan laut, dan sisi satunya langsung berbatasan dengan muara sungai (Armando Coertesao: 2005, 280-281; Sartono Kartodirdjo, ed: 1977, 60).

Pada tahun 1574, kerajaan Aceh dan Johor melangsungkan suatu pertemuan. Keduanya sepakat untuk berbaikan dan bekerjasama mengalahkan Portugis. momen rekonsiliasi ini diperteguh dengan pernikahan Putri Sultan Husain Ali Riayat Syah (1568 - 1575), Raja Aceh kala itu, dengan Pangeran Johor. Mengetahui hal itu, Portugis yang sebelumnya mempunyai pandangan positif mengenai kelangsungan hubungannya dengan Johor, karena sebelumnya Johor membantu Portugis, menjadi murka. Portugis melampiaskan kemarahannya ini dengan menyerang Johor pada 1576 - 1578 (Amirul Hadi: 2010, 52). Dalam konteks ini, pernikahan antara putra dan putri dua kerajaan, adalah sarana mempererat kekerabatan dan relasi diplomatik.

Tatkala Sultan Iskandar Muda memimpin (memerintah 1607 - 1636), ia segera mempersiapkan diri untuk melaksanakan cita-cita pendahulunya, merebut Malaka. Kali ini, Aceh jauh lebih kuat, karena bukan hanya ditunjang oleh persenjataan dan seni berperang yang modern di zamannya, namun juga dipimpin oleh raja yang berapi-api dan memiliki visi yang besar, yakni ingin menciptakan persatuan seluruh Sumatera dan dunia Melayu atau Pan-Melayu (Pan Malaynism) (Teuku Iskandar: 2007, 1718). Langkahnya ini tentu saja akan mendapat batu sandungan jika Malaka tidak segera direbut.

Sultan Iskandar Muda merupakan sosok raja yang visioner. Ia percaya bahwa besarnya suatu kerajaan amat ditentukan sejauh dan sedalam mana pengaruhnya atas negeri-negeri lain. Untuk itu, pekerjaan rumah pertama yang ia benahi adalah memugar armada perang Aceh yang cakap dan kuat untuk segera diandalkan menapaki negeri-negeri lain dan segera menancapkan panji Aceh Darussalam di dalamnya. Angkatan perang Iskandar Muda terdiri dari angkatan laut, angkatan darat, kavaleri, pasukan gajah dan grup meriam.

Berbeda dengan pendahulunya yang langsung menyerang ke Malaka, Iskandar Muda mencanangkan 
penertiban terlebih dahulu kepada negeri-negeri Melayu yang dianggap berkawan dengan Portugis. Berbekal bala pasukan yan kuat, ia menyambangi dan memberi perhitungan kepada mereka yang menolak untuk diajak berdamai dan bersama melawan Portugis. Nuruddin ar-Raniri dalam Bustanussalatin menyebut beberapa di antara negeri Melayu yang ditaklukkan seperti Deli, Johor, Bintan, Pahang, Kedah, Nias dan bahkan Iskandar Muda sempat mengadakan percobaan serangan ke Malaka (Nuruddin ar-Raniri: Tanpa Tahun, 15).

Pada 1613, Bukit Seluyut, ibukota Johor, merasakan bagaimana menderitanya diserang Aceh. Tanpa berbilang waktu lama, pasukan Aceh segera melumpuhkan pusat-pusat kerajaan. Tidak hanya itu, para keluarga kerajaan sebagian ada yang diamankan. Mereka yang berhasil ditangkap adalah Sultan Alaiddin Riayatsyah III, Raja Johor saat itu, adik Sultan Raja Abdullah (Raja Seberang), Putri Kamaliah (Putri Pahang), Bendahara Tun Sri Lanang (Tun Muhammad) dan Raja Siak yang kebetulah sedang bertamu ke Johor. Mereka ditangkap beserta pejabat kerajaan dan sebagian rakyat Johor. Semuanya dinaikkan ke kapal dan dilayarkan ke Aceh (Leonard Y. Andaya: 1971, 28 - 29 dan 56)

Di istana, Sultan Iskandar Muda memperlakukan para tawanan Johor dengan baik. bahkan, mereka ditempatkan di lokasi yang biasanya digunakan untuk menjamu tamu kerajaan. Beberapa waktu kemudian, Sultan Iskandar Muda mengambil Putri Pahang sebagai istri, dan Tun Sri Lanang ia jadikan uleebalang pertama di Samalanga. Hadirnya dua orang ini ikut mempengaruhi kebijakan kesultanan Aceh setelahnya, khususya mengenai bagaimana seharusnya Aceh memperlakukan negeri-negeri Melayu (M. Zainuddin: 1957, 29; M. Dien Madjid: 2011, 3).

Dalam Bustanussalatin di jelaskan bahwa Sultan Iskandar Muda amat menyayangi Putri Pahang. Untuk mengobati hatinya yang kerap rndu dengan kampung halamannya di Johor, Iskandar Muda membangun suatu komplek taman yang ditengahnya terdapat bangunan bernama gunongan. Bentuk bangunan ini berupa bangunan seperti gunung yang di dalamnya terdapat tangga-tangga. Di tengah taman mengalir sungai yang menambah teduh dan semarak suasana taman (Hasjmi: 1983, 166).

Setelah Johor diampuni dan penguasa barunya berjanji untuk sejalan dengan kebijakan Aceh terkait posisi Portugis, keadaan Johor belum juga membaik. Portugis melancaran infiltrasinya dengan mendorong putra Sultan Johor untuk merebut tahta Pahang. Sebelumnya, Peter Williamson Floris, seorang Belanda, mengabarkan bahwa pada 1912, penguasa Johor membakar daerah pinggiran Pahang termasuk Campong Sina (Kampung Cina?). Pembakaran ini menyebabkan kerugian yang besar bagi Pahang. Diketahui bahwa hubungan antara Johor dan Pahang sedang dalam keadaan kurang harmonis.

Hubungan yang kembali terjalin antara Johor dan Portugis membuat Sultan Iskandar Muda murka. Hal ini kemudian mendorong dirinya memerintahkan diadakannya serangan langsung ke Batu Sawar pada September 1615 dan 
dilanjutkan dengan serangan ke Pahang pada 1617. Saat itu yang bertahta di Pahang adalah kemenakan Sultan Johor masa itu, Sultan Mammat Syah. Serangan ini lagi-lagi membuat posisi Johor jauh dari keadaan aman untuk mengembangkan aspek-aspek strategis kerajaannya. Mereka masih percaya bahwa dirinya bisa melepaskan diri dari pengaruh Aceh, meskipun beberapa tokoh penting istana Johor seperti Putri Pahang dan Tun Sri Lanang telah berada di pihak Aceh (R.O. Windstedt: 1932, 38). Sayangnya, percobaan itu tidak lantas membuahkan hasil yang memuaskan.

Carl A. Trochi menyebutkan bahwa di masa awal, tidak seperti negeri Melayu lainnya, Johor adalah kerajaan yang sepi. Populasi manusia di sana juga tidak banyak. Hal ini dkarenakan selama beberapa kesempatan, negeri ini mendapat serangan dari Aceh dan Portugis, sebagaimana yang disebutkan di atas. Wajar jika orang-orang belum menghitung ibukota Johor sebagai lokasi yang aman untuk didiami atau tempat yang cocok untuk mengembangkan usaha. Masa-masa darurat yang kerap dialami Johor ikut membuat negeri ini sulit mencari penghidupan. Di pedalaman, hanya gambir yang menjadi komoditas yang bernilai tinggi. Hubungan perniagaan dengan pulaupulau sekitar juga dilakukan, seperti dengan Singapura (Carl A. Trochi: 2007, 14 dan 19).

\section{Model Diplomasi Aceh dan Johor}

Seperti sudah disampaikan sebelumnya, relasi diplomatik Aceh dan Johor diwarnai oleh keadaan yang fluktuatif. Yang menjadi penyebabnya, adalah kehadiran Portugis di Malaka. Kedua kerajaan memiliki alasan yang kuat untuk melandasi kebijakan yang diambil. Dalam konteks independensi suatu negeri, tentu saja hal ini adalah kenisacayaan, mengingat masingmasing pemerintahan mempunyai visi dan cara pandang yang berbeda dalam mengemudikan biduk besar negerinya.

Hampir setiap persentuhan yang melibatkan hubungan dua kerajaan dalam sistem pemerintahan masa kerajaan adalah bentuk diplomasi. Harold Nicholson mengingatkan bahwa di samping diplomasi heroisme, militer dan perdagangan, ada banyak lagi model diplomasi yang ditemukan pada masa lalu. Hubungan dua kerajaan diliputi oleh perbedaan imaji dan alasan, hidup di antara romantika dan kebijaksanaan, di antara militer dan perniagaan, juga pada anggapan umum dan standarisasi nilai-nilai moral. Di setiap dua kecenderungan itu, tersimpan gagasan dan realitas. Tidak setiap upaya diplomatik membutuhkan gerakan model diplomasi dengan penundukkan atau penanaman pengaruh berdasar pada paradigma penguasa dan yang dikuasai - namun juga membutuhkan model ketenangan (Harold Nicholson: 1942, 55). Model ketenangan yang dimaksud antara lain adalah upayaupaya yang sifatnya khusus, seperti pernikahan, transmisi ilmu pengetahuan, inspirasi dari tokoh negeri lain dan lain sebagainya.

Menarik untuk ditelisik bagaimana model diplomasi yang dilakukan antara Aceh dan Johor. Ditinjau secara akar etimologi, diplomasi merupakan istilah yang lekat dengan dunia negara-bangsa di masa modern. Istilah ini dimunculkan kembali bersandar pada alasan bahwa 
sejak masa lalu sebetulnya sudah ada sistem, mekanisme atau metode diplomasi yang sifatnya endemik, yang tidak selalu sama bentuknya. Dalam kasus Aceh dan Johor, setidaknya didapat dua model, yakni diplomasi politik dan diplomasi intelektual.

Pernikahan merupakan alat pemersatu dua keluarga kerajaan sejak masa yang lama. Kesempatan ini termasuk dalam model diplomasi politik. Samuel A. Meir menyebutkan bahwa sejak akhir Zaman Perunggu, tepatnya di masa Timur Dekat Kuno (Ancient Near East), kedudukan wanita dianggap penting dalam sistem kerajaan. Fungsi wanita di situ dianggap hal yang sakral, utamanya berhubungan dengan hukum waris dan suksesi kerajaan. Kebutuhan akan perempuan dalam mengisi satu pos di dalam pemerintahan telah menjadi suatu karakteristik historis dari pergumulan politik dan budaya manusia (Samuel A. Meir: 2002, 162).

Melalui pernikahan, pembicaran kedua kerajaan akan harapannya lancar terselenggara. Hal yang terpenting adalah biasnya batas antara kerajaan kecil dan kerajaan besar, melebur ke dalam suasana serba hangat khas keluarga besar. Secara teoritis, keadaan ini bisa dimanfaatkan oleh kerajaan kecil guna mendapat bantuan strategis serta perlindungan dari kekuatan musuh yang lebih besar. Bagi kerajaan besar, pernikahan menjadi cara terhalus, klaim kuasa atau pengaruh atas suatu kerajaan. Pernikahan adalah jalan bijaksana untuk menggantikan peperangan dalam upaya penguasaan suatu kerajaan.

Terhitung sejak tahun 1574, hubungan antara Aceh dan Johor sepakat untuk dijalin (Amirul Hadi: 2010, 52). Berbeda dengan angka tahun itu, Zainuddin menyampaikan bahwa terbukanya kran diplomasi Aceh-Johor terjadi saat Aceh diperintah oleh Sultan Salahuddin (1530-1537). Suatu hari, seorang pelaut bernama Laksamana Nadin datang ke istana Aceh. ia mengaku berasal dari Ujung Tanah (Johor). Kedatangannya membawa pesan dari Raja Ali, putra dari Sultan Mahmudsyah, Raja terakhir Malaka yang juga Raja pertama Johor, untuk meminta bantuan Aceh sekaligus meminang putri Aceh menjadi istri Raja Ali. Sultan Mamudsyah sendiri kabarnya belum lama berpulang saat ia melarikan diri ke Kampar. Permintaan Laksamana Nadin diterima, namun untuk masalah pinangan, Sang Laksamana baru bisa meluluskannya asalkan menyerahkan mahar nikah berupa ranubkong haba. Laksamana Ujung Tanah itu akan menyampaikan pesan itu pada junjungannya kelak jia ia pulang.

Beberapa waktu kemudian, datang iring-iringan besar dari Ujung Tanah mengiringi seorang pangeran yang mengenakan busana pengantin. Rombongan ini datang untuk meminang putri Aceh. Setelah syarat mahar nikah diserahkan, pesta pernikahan pun segera diadakan dengan meriah. Selama beberapa waktu, rombongan ini tinggal di Aceh. Laksamana Nadin menjadi juru bicara Ujung Tanah untuk menjajaki kerjasama dengan perangkat istana Aceh. Ujung Tanah sepakat, bersama Aceh, mereka akan memerangi Portugis. Setelah rangkaian upacara dan prosesi pernikahan usai, pihak Ujung Tanah pun pamit pulang. Selepas itu, mereka sudah menjadi sekutu Aceh.

Raja Ali sendiri tatkala sudah kembali ke Ujung Tanah, ditabalkan menjadi 
Sultan Johor kedua, bergelar Sultan Alaiddin Riayatsyah II. Suatu ketika, ia dan istrinya, putri dari Aceh, pergi ke suatu pulau dekat Ujung Tanah. Sebagai bentuk kekeluargaan, dari istana Aceh diutus sepasukan Aceh di bawah pimpinan Panglima Bukit yang berasal dari negeri Lingga Gayo (Aceh Tengah), untuk mengawal perjalanan pasangan kerajaan itu. Pulau yang dituju kemudian ditetapkan sebagai hunian baru bagi rakyat Johor. Setelah dibangun sebuah kota di dalamnya, pulau itu diberi nama pulau Lingga. Nama ini diambil dari negeri asal Panglima Bukit di Lingga yang terletak di dataran tinggi Gayo (Zainuddin: 1961, 396 - 397).

Sejatinya, pernikahan putra-putri dua kerajaan merupakan representasi dari kesamaan posisi dua kerajaan. Dua kerajaan yang berbesanan adalah dua kerajaan independen yang ingin membina suatu hubungan lebih lanjut dan sama-sama mengharapkan hasil yang baik dari hal tersebut. Motif itu direpresentasikan pada kedua mempelai yang saling mengasihi, di mana seyogyanya pasangan yang memadu kasih, akan bersedia berkorban untuk kebahagiaan satu dengan lainnya. Hal yang sama diharapkan oleh kedua kerajaan asal mereka. Pernikahan menjadi puncak gunung es dari mengakarnya suatu kesepakatan politik, ekonomi dan budaya.

Namun, yang terjadi pada kasus Aceh dan Johor, mempunyai motif yang berlainan. Aceh menjadikan ini sebagai wahana memasukkan Johor sebagai wilayah sahabat Aceh, dan Johor menangkap sinyal ini sebagai indikasi akan adanya infiltrasi lebih mendalam dalam urusan rumah tangga istana. Menaggapi hal ini,
Johor tidak tinggal diam dan menjadikan Portugis sebagai rekanan yang sepadan untuk mengimbangi pengaruh Aceh. Dilihat dalam perspektif kebijakan luar negeri Johor, ini adalah cara yang dianggap efektif agar Aceh tidak bebas merasuki kepentingan istana Johor. Namun, dalam sudut pandang Aceh, ini tentu saja adalah bentuk penghianatan terhadap kesepakatan untuk bersama mengusir Portugis.

Pernikahan sebagai startegimendekatkan kepentingan dua kekuatan politik, tidak saja ditemukan dalam dunia Melayu. Dalam beberapa kasus negeri-negeri di belahan dunia lainnya, pernikahan juga dijadikan alat pemersatu atau penghubung terhadap dua kepentingan politik luar atau dalam negeri yang semula berbeda. Kontantinus (312337), Kaisar Romawi yang pertama menggunakan Kristen sebagai agama yang memersatukan wilayah-wilayah Romawi yang terancam disintegrasi, menggunakan pernikahan sebagai salah satu cara memantapkan hubungannya dengan sekutunya.

Konstantinus tidak lagi menimbang, apakah pasangan untuk keluarganya adalah mereka yang berasal dari golongan bangsawan atau petani sekalipun. Licinius, seorang petani yang menapaki kepangkatan militer hingga sampai ke jenjang yang tinggi dan memiliki pengikut yang banyak, menjadi salah satu sekutu raja Romawi ini. Di masa Konstantinus, Licinius adalah penguasa wilayah tengah kerajaan yang terbentang dari sebelah timur provinsi Pannonia hingga sebelah barat Laut Hitam. Oleh para pengikutnya Licinius digelari sebagai imperator yang bermakna penguasa. 
Konstaninus sudah menimbang, dengan ketersediaan pasukannya, ia tidak mungkin menang melawan Licinius. Di sisi lain, Romawi juga memiliki kompetitor lain yakni Maximinus Daia, seorang mantan petani juga mempunyai banyak pengikut. Setelah memikirkan masak-masak, Konstantinus mendekati Licinius guna menawarkan suatu jalinan perdamaian. Licinius setuju. Sebagai pengikat hubungan mereka, Konstantinus menikahkan Licinius dengan saudari tirinya, Konstantia. Antara Licinius dan Konstantia terpaut umur yang cukup jauh. Licinius berusia enam puluh tahun dan Konstantia berumur delapan belas tahun (Susan Wise Bauer: 2016, 4). Pernikahan seperti ini terjadi akibat dikedepankannya alasan politik, ketimbang didasari oleh cinta kedua pasangan itu.

Paska serangan atas Bukit Seluyut pada 1613, Sultan Iskandar Muda terpikat oleh Putri Pahang. Ia pun menjadikan Putri Pahang sebagai istri. Keberadaan putri Pahang, rupanya tidak hanya sebagai penghias kamar kerajaan. Dalam beberapa kesempatan, ia turut membantu pemerintahan Aceh Darussalam. Ia kerap memberikan nasehat kepada suaminya. Berkat permintaan Putri Pahang-lah, Sultan Alaiddin Riayatsyah III, Raja Johor yang ditangkap, terbebas dari hukuman mati. Dalam suatu cerita dikisahkan Putri Pahang pernah memberi saran kepada Iskandar Muda apabila melewati Asahan, hendaknya kapal-kapal Aceh menembakkan meriam sebagai tanda permisi. Hal ini dilakukan agar Asahan tidak salah paham dan menyerang Aceh. Saat itu, Asahan dikenal sebagai negeri yang mempunyai angkatan perang kuat, sehingga bisa saja wilayah ini menjadi lawan yang berat bagi Aceh (Zainuddin: 1957, 129; Mohammad Said: 1981, 274).

Putri Pahang juga ikut terlibat dalam penyususan ratifikasi undang-undang (qanun) kerajaan Aceh Darussalam. Pocut Haslinda dalam bukunya, Perempuan Bercahaya dalam Lintasan Sejarah Aceh, menyebutkan bahwa Putri Pahang juga menyarankan kepada sultan Aceh untuk membentuk semacam Dewan Perwakilan Rakyat yang dinamakan Balai Majelis Mahkamah Rakyat. Komponen ini merupakan kelengkapan sari satuan paket undangundang Aceh yang bernama Hadih Maja (Pocut Haslinda: 2011, 149-152).

Selanjutnya, model diplomasi lain yang dikenal dalam historisitas hubungan Aceh dan Johor pada abad ke 17, adalah diplomasi intelektual. Sejak abad 16, Aceh sudah di kenal sebagai pusat pendidikan dan keilmuan di Asia Tenggara. Di samping itu, di Aceh sudah terdapat badan-badan penerjemahan yang menterjemahkan kitab-kitab berbahasa Arab ke bahasa Melayu, namun dengan tetap menggunakan aksara Arab (Engku Ibrahim Ismail: 1992, 2). Tidak menutup kemungkinan jika kitab-kitab ini sampai ke negerinegeri Melayu, seperti Johor.

Dalam bidang kepengarangan Melayu, kitab Taj al-Salatin dikenal sebagai rujukan raja-raja Melayu, termasuk Aceh, dalam memerintah kerajaannya. Penulis kitab ini bernama Bukhari alJauhari. Sejumlah sarjana berbeda pandangan tentang laqab (sematan atau julukan) al-Jauhari itu. Saleh Partaonan Daulay mengutip dari Teuku Iskandar meyakini bahwa al-Jauhari merujuk pada Johor. R. O. Windstedt dan Liaw 
Yock Fang justru mempercayai bahwa penulis Taj al-Salatin berasal dari Persia (R. O. Winstedt: 1991, 95 - 97; Liaw Yock Fang: 1993, 70). Jika pada penelitian lanjutan ditemukan kebenaran bahwa penulis Taj al-Salatin adalah dari Johor, maka Aceh mengunduh informasi penting dari kerajaan Johor di bidang ilmu pengetahuan kepemerintahan.

Kedatangan Tun Sri Lanang ke Aceh Darussalam ikut mewarnai geliat intelektual Aceh. Ia adalah sosok negarawan juga ilmuwan. Tun Sri Lanang merupakan penulis kitab Sulalatussalatin. Kitab ini berisi sejarah negeri-negeri Melayu mulai dari masa Iskandar Zulkarnain sampai ke masa kedatangan Faranggi (Portugis) ke Malaka. Bahkan, dengan tegas Nuruddin ar-RanirimengutipkitabSulalatussalatin karangan Tun Muhammad (Tun Sri Lanang) ketika menyisipkan bahasan sejarah Melayu di Bustanussalatin-nya (Nuruddin ar-Raniri: Tanpa Tahun, 1). Hal ini menunjukkan bahwa sudah ada semacam notasi di bidang karya tulis dan sekaligus membuktikan bahwa di masa itu sudah ada transmisi informasi ilmu pengetahuan. Besar kemungkinan Nuruddin telah terlebih dahulu membaca Sulalatussalatin sebelum ia menulis tentang bab sejarah Melayu di Bustaussalatin.

R. J. Wilkinson mengutip suatu informasi dari R. O. Windstedt tentang genealogi "Bendaharas dan Tomenggongs" tentang asal-usul Tun Sri Lanang sebagai berikut (R. J. Wilkinson: 1933, 148):
“... But Tun Sri Lanang summarizes his ancestry in words on which the light of scholarship has only recently been thrown: Tun

Muhammad nama-nya, Tun Seri Lanang timang-timangnya, Paduka Raja gelarannya, Bendahara, anak orang kaya Paduka Raja, chuchu Bendahara Seri Maharaja, chichit Bendahara Seri Narawangsa, piut Bendahara Seri Maharaja, anak Seri Nara Diraja Tun Ali, anak baginda Mani Purindam, kaddasa Allahu sirrahum, Melayu bangsa-nya, dari bukit Si-guntang Mahamiru, [Malakat negeri-nya Batu Sawar daru 's-sallama] ..."

Kehadiran Tun Sri Lanang di Samalanga, tidak dikenang sebagai seorang tawanan, melainkan karena dedikasinya membangun kampung itu. Sebelum ia diangkat menjadi uleebalang pertama di Samalanga, namanya sudah akrab di telinga penduduk Samalanga sebagai guru masyarakat. Ia mengajarkan masyarakat setempat pengetahuan dasar ilmu agama dan bahasa Arab. Di waktu yang lain, ia juga memperkenalkan teknik bercocok tanam dan memperbaiki perahu-perahu yang rusak. Berkat keilmuan serta keterampilannya inilah, nama Tun Sri Lanang harum di kalangan penduduk Samalanga. Ia tidak menggunakan pendekatan layaknya seorang bangsawan menghampiri rakyatnya. Ia mengenakan pakaian seperti penduduk kebanyakan sehingga terasa tidak ada sekat antara dirinya dan orang di sekitarnya (M. Dien Madjid: 2011, 3).

Tun Sri Lanang agaknya berhasil meyakinkan Sultan Iskandar Muda, bahwa kehadiran pendatang sepertinya, apalagi dari kerajaan yang sempat dianggap sebagai musuh Aceh, tidaklah hanya menjadi beban kerajaan Aceh. 
Tun Sri Lanang tidak lagi melihat di mana ia hidup. Dari sumber lisan yang didapat $M$. Dien Madjid dari Pocut Haslinda, Tun Sri Lanang sudah menganggap Samalanga sebagai tempatnya berkarya. Meskipun di Aceh ia sempat mengalami periode yang sulit untuk tokoh sekelas pejabat tinggi istana lainnya yang terpaksa tinggal di kerajaan yang menangkapnya, tidak lantas membuat dirinya mengurung diri dan abai terhadap masalah sosial yang di hadapi masyarakat sekitarnya.

Dalam suatu cerita lokal, dikisahkan bahwa Tun Sri Lanang sempat terlibat kompetisi dengan para tokoh masyarakat Samalanga terkait kedudukan uleebalang Samalanga. Suatu ketika, Sultan Iskandar Muda sedang mencari pemimpin yang cakap untuk Samalanga, kelak yang menduduki jabatan itu akan digelari uleebalang pertama Samalanga. Raja Aceh itu mengadakan sayembara, barang siapa yang jari tangannya cocok mengenakan salah satu cincin yang dimilikinya, maka ia berhak menjadi penguasa Samalanga.

Mendengar kabar tersebut, terdapat dua belas orang tokoh masyarakat asal Samalanga yang tergerak untuk mencoba sayembara Sultan Aceh. Mereka pun merencanakan keberangkatannya ke ibukota Aceh. Putri Pahang yang sudah lama mengetahui saudaranya hidup di Samalanga meminta pada Tun Sri Lanang untuk menyertai kedua belas pembesar Samalanga itu sebagai nelayan yang mengantarkan mereka. Sesampainya di istana Aceh, kedua belas tokoh Samalanga segera mencoba cincin Sultan Iskandar Muda, namun tidak ada satupun dari mereka yang ukuran jarinya cocok dengan lubang cincin itu.

Tun Sri Lanang berkesempatan pula mencoba sayembara itu. Belum jelas bagaimana jalan ceritanya seorang nelayan diperkenankan mengikuti sayembara yang biasanya hanya diperuntukkan bagi ruling class dalam alam kerajaan seperti itu. Namun, di sinilah letak keunikan cerIta rakyat. Sesekali ada twist yang yang tidak terduga sebelumnya. Setelah mencoba cincin itu, rupanya ukurannya cocok dengan jari Tun Sri Lanang. Akhirnya ditetapkanlah Tun Sri Lanang sebagai penguasa Samalanga bergelaruleebalang Samalanga (M. Dien Madjid: 2011, 6).

Nama Nuruddin ar-Raniri dalam konteks sejarah sastra Indonesia, sepertinya lebih populer dibanding Tun Sri Lanang. Padahal di negara-negara jiran seperti Malaysia dan Singapura, nama Tun Sri Lanang begitu dikenal. Ini yang menjadi suatu keunikan, tokoh ini lahir, besar dan berkiprah di Johor, namun sempat membaktikan diri, bahkan wafat dan dimakamkan di Aceh, tepatnya di Samalanga. Beberapa waktu sebelum penulis mengunjungi makamnya tahun 2011, makam Tun Sri Lanang sempat terbengkalai, dan penduduk sekitar tidak begitu mengenal sosok dan kebesaran Tun Sri Lanang. Ini menjadi hal yang aneh, namun nyata adanya.

Beberapa waktu sebelum tahun 2011, makam Tun Sri Lanang di Kutablang, Samalanga sempat berada dalam kondisi yang mengenaskan. Kondisi tidak terawat dan abainya perhatian terhadap situs ini, menyebabkan semakin langkanya informasi mengenai keberadaannya. Berkat perhatian beberapa ahli warisnya, seperti Pocut Haslinda Azwar, makam ini dipugar 
dan sejarah mengenai Tun Sri Lanang ditulis dan diperkenalkan. Seminar yang diselenggarakan oleh pemerintah Bireun bekerjasama dengan ahli waris Tun Sri Lanang pada Desember tahun 2011 memugar kembali kesejarahan Tun Sri Lanang dalam dinamika penulisan sejarah Aceh.

Wacana Tun Sri Lanang memang meruapakan satu serakan dari banyak lagi kepingan tema sejarah Aceh yang masih belum dikenal. Tahun 2011 menjadi tonggak penting bagi riwayat Tun Sri Lanang, yang melalui seminar dan penulisan buku mengenainya, semakin dikenal oleh masyarakat luas. Tokoh semacam Tun Sri Lanang seharusnya lebih banyak ditelisik keberadaannya lebih lanjut, mengingat kedudukannya di istana Johor adalah sebagai salah satu penasehat sultan. Kini, Tun Sri Lanang adalah juga milik bangsa Indonesia dan kaum intelektual serta sejarawan negeri ini juga mempunyai kewajiban untuk mengurai sosok dan dedikasinya secara lebih mendalam.

Dua jenis model diplomasi ini, mungkin saja bersifat umum, namun bisa pula bersifat khusus. Pernikahan dan transmisi intelektual, merupakan dua peristiwa yang umum terjadi dalam sejarah. Walaupun begitu, peristiwa yang mengitarinya atau yang memantiknya terjadi, bisa saja berbeda. Dalam kasus diplomasi Aceh dan Johor, yang menjadi pembedanya tentu saja adalah kehadiran Portugis yang menyumbang dampak besar bagi perubahan polapola hubungan antarkerajaan yang sifatnya tradisional, atau bentuk-bentuk komunikasi yang sebelumnya lumrah ditemui, menjadi berubah.

\section{Kesimpulan}

Aceh maupun Johor merupakan kerajaan yang mempunyai historisitas panjang dalam berdiplomasi. Pada dasarnya, hubungan kedua kerajaan dilandasi oleh kebutuhan saling mengambil manfaat. Bagi Aceh, bekerjasama dengan Johor adalah satu langkah dari banyak upaya menghimpun kekuatan dunia Melayu untuk bersama mengusir Portugis. Bagi Johor, bersahabat dengan Aceh adalah usaha untuk memperoleh perlindungan dan keamanan selain membawa manfaat-manfaat lain seperti di bidang perdagangan, kebudayaan dan keilmuan.

Meskipun demikian, Johor melihat, terdapat potensi lain yang ada dalam niat diplomasi Aceh. Seiring dengan pergantian kekuasaan ke tangan raja yang memiliki visi perluasan pengaruh atas dunia Melayu, Johor menilai Aceh sedang menjajaki kesempatan turut campur dalam kebijakan-kebijakan Johor. Oleh sebab itu, secara sepihak, Johor membangun hubungan baik dengan Portugis, agar dirinya tetap memperoleh perlindungan, ketika saatsaat genting akibat hubungan dengan Aceh muncul. Langkah itu, dinilai Aceh sebagai suatu bentuk penghianatan dan Johor layak dihukum berat, seperti serangan atas Bukit Seluyut, ibukota mereka.

Terdapat benang merah yang mengaitkan kedua kerajaan, yakni sama-sama ingin mengamankan kepentingan mereka. Keduanya tidak bisa dipersalahkan, mengingat secara teoritis, kebijakan tertinggi suatu pemerintahan diputuskan secara internal, tanpa melibatkan pihak dari luar istana.

\section{Daftar Pustaka}


Andaya, Leonard Y. "The Kingdom of Johor, 1641-1728: A Study of Economic and Political Developments in The Straits of Malacca", Tesis, Cornell University, 1971.

Ar-Raniri, Nuruddin. Bustanussalatin bait 12 dan 13, Perpustakaan Nasional Republik Indonesia dengan nomor panggil ML 422.

Azwar, Pocut Haslinda Syarhrul. Perempuan Bercahaya dalam Lintasan Sejarah Aceh, Jakarta: Yayasan Tun Sri Lanang, 2011.

Bauer, Susan Wise. Sejarah Dunia Abad Pertengahan, Terj. Aloysius Prasetya A. Jakarta: Elexmedia Komputindo, 2016.

Braudel, Fernand. Civilization and Capitalization 15-18 ${ }^{\text {th }}$ : Volume III, The Wheel of Commerce, Tran. Sian Reynolds, London: William Collin Sons \& Co Ltd, 1982.

Birmingham, David. A Concise History of Portugal, Cambridge: Cambridge University Press, 2003.

Chauduri, K. N. Trade and Civilization in The Indian Ocean, Cambridge: Cambridge University Press, 1989.

Cohen, Raymond dkk. Amarna Diplomacy, Maryland: John Hopkins University Press, 2002. Artikel Samuel A. Meir, "Marriage and Diplomacy".

Cortesao, Armando. The Suma Oriental of Tome Pires, Vol. II, New Delhi: Asian Educational Services, 2005.

Curtin, Philip D. Cross-Cultural Trade in World History, Cambridge UK: Cambridge University Press, 1998.
Fang, Liaw Yock. Sejarah Kesusasteraan Melayu Klasik 2, Jakarta: Air Langga, 1993.

Hadi, Amirul. Aceh; Sejarah, Budaya dan Tradisi, Jakarta: Yayasan Obor Indonesia, 2010.

Hall, D.G.E. Sejarah Asia Tenggara, Terj. I. P. Soewarsha, Jakarta: Usaha Nasional, 1988.

Hamka. Sejarah Umat Islam, jilid 4. Bukittinggi: N.V. Nusantara, 1961.

Hasjmy, A. Kebudayaan Aceh dalam Sejarah, Jakarta: Penerbit Beuna, 1983.

Iskandar, Teuku. "Aceh ad a MuslimMalay Cultural Centre (14th - 19 th Century", makalah dipresentasikan pada First International Conference Aceh and Indian Ocean Studies, pada 24 - 27 Februari 2007 di Banda Aceh.

Ismail, Engku Ibrahim. Syekh Daud Al Fatani Satu Analisis Peranan dan Sumbangannya Terhadap Khazanah Islam di Nusantara, Kuala Lumpur: Universiti Kebangsaan Malaysia, 1992.

Jayne, J.S. Vasco Da Gama and His Successors, London: Methuen \& Co. Ltd, 1910.

Kartodirdjo, Sartono, ed. Masyarakat Kuno dan Kelompok Sosial, Jakarta: Bhratara Karya Aksara, 1977.

Lombard, Denys. Kerajaan Aceh; Jaman Sultan Iskandar Muda (1607-1636), Terj.Winarsih Arifin. Jakarta: Balai Pustaka, 1986.

Madjid, M. Dien. "Tun Sri Lanang dalam Lintasan Sejarah dan Hubungannya dengan Perkembangan Islam di Aceh", 
makalah disampaikan dalam "Seminar Ketokohan Tun Sri Lanang" di Bireuen, Aceh pada 28 Desember 2011.

Nicholson, Harold. Diplomacy, London: Oxford University Press, 1942.

Said, Mohammad. Aceh Sepanjang Abad Jilid 1, Medan: P.T. Percetakan dan Penerbitan Waspada Medan, 1981.

Soucke, Svat, "The Portuguese and The Turks in Persian Gulf" dalam Dejaniah Couto and Rui Manuel Loureiro, ed. Revisiting Hormuz; Portuguese Interactions in the Persian Gulf Region in the Early Modern Period, Germany: Calouste Gulbenkian Foundation, 2008.

Souza, Manuel de Faria Y. "Portuguese History of Malacca", dalam Journal Straits Branch Of The Royal Asiatic Society, No. 17, 1887.

Trochi, Carl A. Prince of Pirates; The Tomenggongs and the Developments of Johor and Singapore 1764 - 1885, Singapore: NUS Press, 2007.

Van Loon, Hendrik Willem. The History of Mankind, USA: Boni \& Liveraight Inc., 1922. . A History of Malay Classical Literature, Petaling Jaya: Eagle Trading Sdn. Bhd, 1991.

Winstedt, Richard. "The Early Rulers of Perak Pahang and Acheh" dalam Journal of The Malayan Branch of The Royal Asiatic Society, Vol. X, No. 1, Januari 1932.

- Malaya and Its History, Great Britain: The Anchor Press, 1933.
Wilkinson, R. J. "The Sri Lanang Pedigree" dalam Journal of The Malayan Branch of The Royal Asiatic Society, Vol. XI, No. 2, Desember 1933.

Zainuddin, H.M. Singa Atjeh. Medan: Pustaka Iskandar Muda, 1957. . Tarich Atjeh dan

Nusantara, jilid 1, Medan:

Pustaka Iskandar Muda, 1961.

Zakaria, Abdul Aziz bin. Sejarah Kenaikan dan Kejatohan Kekuasaan Portugis di Melaka, London: Macmillan \& Co, 1953.

\section{Online}

Entri "Treaty of Tordesillas" dalam Max Planck Encyclopedia of Public International Law, diunduh dari http:// opil.ouplaw.com. Pada pukul 14.22 WIB, Senin 5 Desember 2016. 
